\title{
A Sistematização dos Saberes Docentes em suas Relações com a Formação Inicial de Professores de Química
}

\author{
Débora Lázara Rosa ${ }^{1}$ \\ Ana Néry Furlan Mendes² \\ Andrea Brandão Locatelli ${ }^{3}$
}

\begin{abstract}
Resumo
Este trabalho objetiva sistematizar os saberes que potencialmente colaboram na constituição da identidade docente, como saberes experienciais em processo, saberes da ação pedagógica, produção de saberes na relação interinstitucional e saberes publicizados envolvidos na formação inicial de professores de Química participantes do Programa Institucional de Bolsa de Iniciação à Docência - Pibid - na Universidade Federal do Espírito Santo. Por meio da análise sistemática dos relatórios de atividades anuais enviados à Coordenação de Aperfeiçoamento de Pessoal de nível Superior $\square$ Capes - foram elaboradas categorias segundo a metodologia de análise de conteúdo de Bardin, permitindo tecer considerações acerca dos saberes docentes pertinentes à profissionalização na formação da identidade de professores de Química. A publicização desses saberes investigados no local de trabalho dos futuros professores oportuniza a reflexão na ação e anuncia conhecimentos antes "armazenados" na jurisprudência particular de cada profissional, levantando questões relevantes pautadas na epistemologia da prática.
\end{abstract}

Palavras-chave: Saberes docentes. Pibid Química. Identidade docente. Formação inicial.

1 Professora do Departamento de Educação no Centro Universitário Norte do Espírito Santo da Universidade Federal do Espírito Santo. Mestrado em Ensino da Educação Básica pelo Ceunes/Ufes, São Mateus/ES - área de Formação Inicial de Professores de Química. deboralazararosa@gmail.com

${ }^{2}$ Graduação em Química Industrial e Bacharelado em Química pela Universidade Federal do Rio Grande do Sul; Doutorado na Universidade Federal do Rio Grande do Sul. ananeryfm@gmail.com

3 Graduação em Educação Física (1993), Mestrado (2007) e Doutorado (2012) em Educação pela Universidade Federal do Espírito Santo/Ufes. dealocatelli@gmail.com 


\title{
THE SYSTEMATIZATION OF TEACHING KNOWLEDGE IN ITS RELATIONS WITH THE INITIAL TRAINING OF TEACHERS OF CHEMISTRY
}

\begin{abstract}
This work aims to systematize the knowledge that potentially collaborate in the creation of the teacher identity, as experiential knowledge in process, the pedagogical action knowledge, knowledge production in the inter - institutional relationship and publicized knowledge involved in the initial training of Chemistry teachers participating in the Institutional Program of the Initiation to Teaching Scholarship - Pibid in the Universidade Federal do Espírito Santo. Through systematic analysis of the annual activity reports sent to Higher Level Personnel Training Coordination - Capes, they were organized according to Bardin content analysis methodology, allowing some considerations about the teaching knowledge relevant professionalization in the training of Chemistry teachers' identity. The publicity of this knowledge investigated in prospective teachers the workplace, provides an opportunity to reflect on action and announces knowledge before "stored" in the particular jurisprudence of each professional, raising relevant issues guid by the epistemology of practice.
\end{abstract}

Keywords: Teaching knowledge. Pibid Chemistry. Teaching identity. Initial formation.

Recebido em: 30/3/2017

Aceito em: 22/11/2017 
Analisar os saberes da prática pedagógica partindo da dimensão do que é ensinar e quais as suas relações com os saberes docentes é um ponto inicial de reflexão dessa complexa atividade profissional. Gauthier (2013, p. 18) identifica as dimensões dos saberes docentes acerca da reflexão do que é ensinar, quais os saberes envolvidos na prática pedagógica ao rever historicamente o debate referente aos atributos docentes e considera que, desde o início do século 20, já se articulavam projetos de pesquisa para tornar o ensino mais eficiente. Em contraposição, o autor aponta que somente a partir dos anos 70 ganham repercussão as pesquisas realizadas na América e na Europa integrando os saberes docentes e suas relações com a sala de aula como local de pesquisa. Sobre o ato de ensinar, Feldmann (2009, p. 72) faz uma relação entre o ensino e a constante articulação com os saberes intrínsecos aos sujeitos envolvidos no processo: "As pessoas não nascem educadores, se tornam educadores, quando se educam com o outro, em um processo permanente de apropriação, mediação e transformação do conhecimento mediante um projeto existencial e coletivo de construção humana."

Ainda segundo Gauthier (2013, p. 19), ensinar envolve habilidades e atitudes a partir da constituição da identidade docente, e analisa o ato de ensinar: "A ciência do ensino é muito mais uma ideia a ser guardada no velho baú das utopias educativas do que uma tarefa já concretizada." Assim, ao analisar a complexa tarefa de ensinar associando-a à ciência do ensino e suas atribuições, Gauthier (2013, p. 19) destaca a importância de se estudar os saberes próprios ao ensino e as reflexões dos trabalhos de pesquisas que fundamentam sua profissionalização:

Com efeito, a pesquisa de um repertório de conhecimentos do ensino permite contornar dois obstáculos fundamentais que sempre se interpuseram à Pedagogia: primeiro o da própria atividade docente, por ser uma atividade que se exerce sem revelar os saberes que lhes são inerentes; segundo, o das ciências da educação, por produzirem saberes que não levam em conta as condições concretas de exercício do magistério. 
Nesse sentido, os saberes da profissão apresentam-se como aporte aos diversos outros saberes que fundamentam a prática docente, que segundo Gauthier (2013), formam uma espécie de reservatório no qual o professor se abastece, com o intuito de atender às demandas de seu cotidiano profissional, propondo articulações entre estes (Figura 1).

Os saberes disciplinares fazem referência aos saberes advindos das pesquisas sobre as disciplinas específicas. Assim, de acordo com Tardif, Lessard e Lahaye (1991, p. 59), esses saberes "correspondem aos saberes que se encontram à disposição da nossa sociedade tal como se acham hoje integrados à universidade sob a forma de disciplinas".

Figura 1 - Esquematização do reservatório de saberes

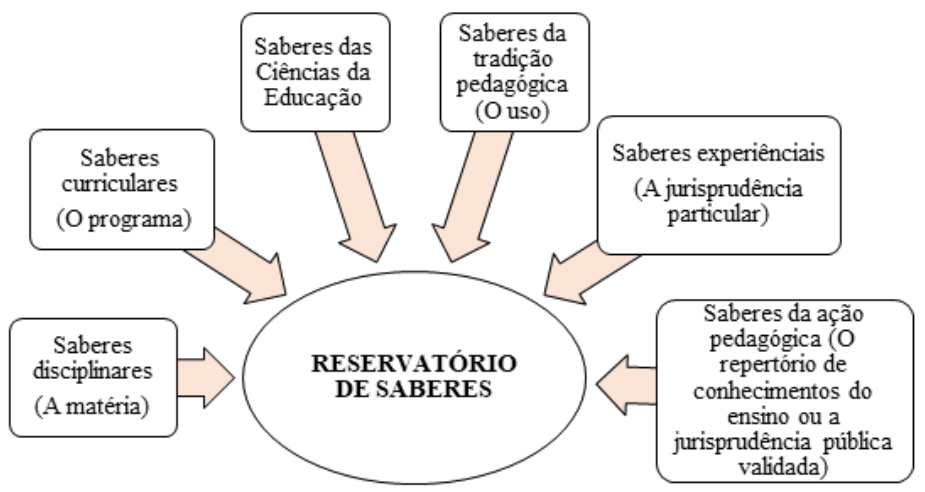

Fonte: Gauthier (2013, p. 29, adaptado).

Na prática docente esse saber movimenta-se alinhado a outros saberes, dando suporte ao fazer docente. Maldaner (2013, p. 163) refere-se às especificidades do ensino de Química e aos que estudam essa Ciência: "Para considerarmos alguém iniciado em Química não basta que saiba decifrar a simbologia química, é necessário que conheça também o tipo de pensamento usado nessa matéria e entenda as especificidades metodológicas da produção do conhecimento químico".

Ainda são recorrentes programas de formação docente pautados na unilateralidade do conhecimento, atribuindo apenas às disciplinas específicas a responsabilidade pela formação docente, enquanto as pedagógicas apresentam-se 
como suporte ao curso de Licenciatura, uma vez que a inversão (ou união) desses papéis nos processos formativos vem contribuindo para manutenção dos saberes docentes muitas vezes restritos aos conhecimentos específicos, inviabilizando a sua articulação na prática pedagógica.

Os saberes experienciais em processo fundamentam-se, segundo Gauthier (2013), na vivência do docente, que muitas vezes os tomam como hábito do seu fazer pedagógico. Restringem-se aos pares professores supervisores e aos bolsistas do Pibid, que por sua vez não são publicizados e verificados via pesquisas acerca da prática docente no local em que se concretiza. Caracteriza-se como um saber tácito, individualizado perante a natureza que se apresenta, e fica restrito à sala de aula e/ou ao momento no qual ele ocorre. Esses saberes são fonte de compreensão do trabalho docente, mas ainda se restringem à jurisprudência particular dos professores, ou seja, o processo de julgamento docente em relação aos saberes advindos da experiência e as ações que subsidiam os entraves na resolução de situações-problemas que se apresentam no cotidiano da prática pedagógica (GAUTHIER, 2013, p. 315), sendo necessária sua compreensão e entendimento da influência na epistemologia da prática. Segundo Tardif (2014, p. 255), "A epistemologia da prática profissional é o conjunto dos saberes utilizados realmente pelos profissionais em seu espaço de trabalho cotidiano para desempenhar todas as suas tarefas."

Nos saberes da ação pedagógica, legitimar os saberes docentes profissionalmente por meio da pesquisa e de sua publicação é apontado por Gauthier (2013) como fundamental à constituição da identidade docente. Esse seria um meio de aperfeiçoamento da prática educativa, mas também identifica os seguintes pontos como determinantes à validação da prática pedagógica:

- Dimensão epistemológica - natureza dos saberes envolvidos no processo.

- Dimensão política - validar os saberes e as práticas que os docentes dominam.

- Formalização dos saberes - por meio da pesquisa e divulgação aos meios competentes acerca dos processos que se desenvolvem nesse campo do saber. 
Foerste (2005, p. 91) explicita que a colaboração estabelecida entre universidade e escola de Educação Básica na formação de professores data da década de 80. Esse movimento de parceria, segundo o autor, visa a compreender a dinâmica que se estabelece nos currículos dos cursos de formação de professores, a partir da articulação de práticas colaborativas entre instituições superiores de ensino e as escolas de Educação Básica. Sobre essa expectativa de integração, Foerste (2005, p. 92) destaca:

Nesse movimento denominado parceria estão sendo desenvolvidas atividades articuladas na formação inicial e em serviço. A parceria parece caracterizar-se como um movimento interinstitucional de construção de um novo paradigma de formação de professor [...] envolvendo principalmente alunos (graduandos), docentes da escola básica e professores da universidade.

As pesquisas acerca de como se estabelecem as divisões de trabalho e as relações constituídas a partir dessa interação, contudo, ainda necessitam ampliações acerca de suas relações com a constituição da identidade docente (FOERSTE, 2005, p. 120). No caso de professores da Educação Básica, ainda é necessário superar as condições de trabalho que inviabilizam a pesquisa em seu ambiente profissional, promover condições efetivas de formação, orientação e disponibilidade de tempo e espaço para que efetivamente o professor tenha capacidade de refletir com os sujeitos da escola e com sua experiência profissional sobre caminhos que possam conduzir às atividades de pesquisa dentro do espaço escolar.

Charlot (2012) afirma que pesquisar e ensinar nem sempre convergem entre si, devido à dinâmica da sala de aula, visto que o professor na condição de pesquisador de sua prática nem sempre consegue dar conta das questões profissionais (complexidade no ensino) e também dos entraves que se apresentam em sua rotina de trabalho, aliados à demanda da reflexão que os processos de pesquisa exigem de seus autores. Tardif $(2000$, p. 7) cita em seu texto acerca da formação continuada: "Os conhecimentos profissionais são evolutivos e progressivos e necessitam, por conseguinte, uma formação contínua e continuada. Os profissionais devem, assim, autoformar-se e reciclar-se através de diferentes meios, após seus estudos universitários iniciais". 
Huberman (1992), por sua vez, estabelece a interação entre pesquisadores e professores, como fonte de conhecimento da prática educativa com todas as suas soluções e problemas. Essa interação também se constitui a partir do âmbito particular advindo dos saberes experienciais, para a divulgação pública dos saberes da ação pedagógica acerca dos conhecimentos do ensino como forma de superação dos entraves pedagógicos que se apresentam nos processos de formação docente.

Com o propósito de analisar a constituição do trabalho docente a partir das ações desenvolvidas pelos licenciandos que participam do Pibid, serão tratados os saberes docentes que potencialmente agregam atributos à constituição da identidade docente, por exemplo, Saberes Experienciais em Processo, os da Ação Pedagógica, a Produção de Saberes Interinstitucional e a Publicização dos Saberes Docentes. São saberes que se completam, articulam-se e se constituem uns dos outros, embora todos eles se relacionem de maneira mútua e horizontal, cada qual com suas contribuições e juntos por uma proposta de reflexão dos saberes docentes.

\section{Caracterização da Pesquisa}

Cada pesquisa permeia saberes e produções que vêm ao encontro das expectativas do pesquisador. A este, por sua vez, cabe a responsabilidade de interpretar, analisar e tecer relações advindas de olhares e saberes outros que sustentarão suas considerações concernentes à pesquisa.

Como objeto da análise de conteúdo, as mensagens expressas nas fontes de pesquisa tendem a indicar, por meio da forma escrita, verbal ou sinalizada o significado que se deseja expressar. Assim, esse movimento de expressão caracteriza-se por um conjunto de ações que despontam por intermédio de seus produtores de forma pessoal e coletiva. A partir das percepções de outros incorporados na análise do objeto de estudo, Varlotta (2002) enfatiza esse posicionamento, "Os diferentes modos pelos quais o sujeito se inscreve no texto 
correspondem a diferentes representações que tem em si mesmo como sujeito e do controle que tem dos processos discursivos textuais com que está lidando quando fala ou escreve."

O delineamento da pesquisa engloba todas as etapas do processo, e tende a revelar um panorama que se estreita entre teoria e prática. Com base nos pressupostos que fundamentam a abordagem da pesquisa aqui apresentada, Gatti e André (apud WELLER; PFAFF, 2013, p. 30) apontam a introdução de métodos qualitativos na educação como "uma abordagem que defende a visão holística dos fenômenos, isto é, que leve em conta todos os componentes de uma situação em suas interações e influências recíprocas”. A abordagem qualitativa expressa as relações entre os licenciandos participantes do Pibid envolvidos na pesquisa e suas interações com os demais sujeitos, mobilizando saberes que potencialmente contribuem para a formação da identidade docente.

Foram analisados os relatórios anuais enviados à Capes pelos coordenadores institucionais responsáveis por unificar os relatórios de cada subprojeto da IES e dar encaminhamento. Nesta pesquisa foram analisados os relatórios dos subprojetos de Química da Universidade Federal do Espírito Santo dos campi de São Mateus, Vitória e Alegre, pertinentes às atividades realizadas pelos bolsistas do Pibid do curso de Licenciatura em Química. Foi selecionado o período de 2012 a 2014 devido à padronização do modelo de relatório pela Capes. Essa padronização ocorreu a partir do ano de 2012, mediante um modelo de relatório para todas as IES participantes do programa Pibid, contemplando informações como: atividades artísticas e experimentais, clube de Ciências e Matemática; monitoria; sequências didáticas e metodologias diferenciadas com abordagem CTSA; desenvolvimento de material didático; feiras; saraus; vivências formativas; seminários interinstitucionais e apresentação de trabalhos em eventos. A escrita do relatório fica a cargo do coordenador de área, que é o docente da IES responsável pelo subprojeto e pelos bolsistas.

A pesquisa apresentada pode ser qualificada como documental, que segundo Gil (2008, p. 66), pelo fato de os documentos já terem sido submetidos a certo tipo de análise, classifica-se como documentos de segunda mão. Nas 
palavras do autor, a pesquisa documental "vale-se de materiais que não receberam ainda um tratamento analítico, ou que ainda podem ser reelaborados de acordo com os objetivos da pesquisa".

A análise dos relatórios enviados à Capes nos forneceu um panorama das ações que foram desenvolvidas pelos licenciandos participantes do Pibid, das atividades planejadas e executadas em escolas de Educação Básica, a movimentação de saberes entre os pares envolvidos na dinâmica estabelecida pelo trabalho dos licenciandos, bem como os materiais produzidos e enviados a eventos científicos.

Enfatizando o tratamento de dados, optamos por classificar as atividades discriminadas nos relatórios de acordo com categorias referentes aos saberes docentes abordados no referencial teórico. Assim, segundo Bardin (2011, p. 148): "Classificar elementos em categorias impõe a investigação do que cada um deles tem em comum com outros. [...]. A categorização tem como primeiro objetivo (da mesma maneira que a análise documental) fornecer, por condensação, uma representação simplificada dos dados brutos”.

Foram estabelecidas categorias de análise a partir da relação instituída entre as atividades desenvolvidas e os saberes docentes que as envolvem, com o intuito de sistematizar quais saberes docente têm sido mobilizados na formação inicial de professores de Química participantes do Pibid na Ufes.

Em relação às categorias de análises, buscamos sistematizar as ações desenvolvidas pelos bolsistas de iniciação à docência participantes do Pibid e suas relações com os saberes movimentados pelo fazer docente. Nesse sentido, Gatti (2004, p. 15) propõe três tipos de tratamentos específicos para coleta de dados: os categóricos, os ordenados e os métricos. No presente trabalho de pesquisa são utilizados os dados categóricos, assim definidos pela a autora: "Os dados categoriais são aqueles que apenas podemos colocar em classificações (classes) e verificar sua freqüência nas classes. [...] Categorizações permitem agrupamento segundo alguma característica, discriminando um agrupamento do outro." 
Esse tipo de tratamento permite estabelecer grupos de atributos que alinhem características pertinentes à gama de saberes que são mobilizados nas atividades desenvolvidas pelos licenciandos participantes do Pibid. De acordo com Gatti (2004, p. 13), analisar quantitativamente os dados de uma pesquisa e alinhar aos aspectos qualitativos apresentam-se como uma opção metodológica útil, haja vista a natureza dos processos educativos:

Os métodos de análise de dados que se traduzem por números podem ser muito úteis na compreensão de diversos problemas educacionais. Mais ainda, a combinação destes tipos de dados, oriundos de metodologias qualitativas, pode vir a enriquecer a compreensão de eventos, fatos, processos. As duas abordagens demandam, no entanto, o esforço de reflexão do pesquisador para dar sentido ao material coletado e analisado.

Nas categorias estabelecidas foram consideradas como parte integrante de cada uma delas as seguintes atividades desenvolvidas pelos monitores:

A produção de saberes experienciais em processo é caracterizada por um saber que se fundamenta na epistemologia da prática, articulando as diversas competências que o profissional necessita para atuar durante o processo educativo. De acordo com Tardif (2014, p. 153), “[...] a prática educativa e o ensino são formas de agir plurais que mobilizam diversos tipos de ação aos quais estão ligados saberes específicos”. Assim, a produção de saberes em processo convida o bolsista a articular seus conhecimentos teóricos da disciplina com ações como as monitorias, Clube de Ciências e Matemática, Exposições, Feiras, Sarau e Demonstração e Produção de Experimentos/Organização de Laboratórios.

Os saberes da ação pedagógica representam a movimentação de saberes técnicos e pedagógicos, que são experimentados na sala de aula, permitindo ao bolsista avaliar e compreender o trabalho docente como um movimento de superação da dicotomia entre teórico e prático, que está tão presente nos cursos de formação docente, saberes estes que corroboram com Gauthier (2013, p. 33):

O saber da ação pedagógica é o saber experiencial dos professores a partir do momento em que se torna público e que é testado pelas pesquisas realizadas em sala de aula. O julgamento dos professores e os motivos que lhes servem 
de apoio podem ser comparados, avaliados, pesados, a fim de estabelecer regras de ação que serão conhecidas e aprendidas por outros professores. [...] Embora presente em toda prática profissional, uma jurisprudência particular não tem nenhuma utilidade para a formação de professores e não leva a um maior reconhecimento do status profissional do docente.

Foram sistematizados a esses saberes as metodologias de ensino, produção de material didático e construção de material de registro, identificadas nos relatórios do Pibid.

Por meio da produção de saberes docentes na relação interinstitucional, identificaram-se as interfaces estabelecidas entre os sujeitos da Universidade e das escolas de Educação Básica, ao vivenciar processos formativos em seminários interinstitucionais, no diálogo entre os professores universitários e os professores da Educação Básica, entre os pibidianos e os demais atores envolvidos nesse processo colaborativo. Essa relação pode assim ser refletida, segundo Foerste (2005, p. 120): “A formação profissional do professor está experimentando a construção de um novo paradigma, com a definição de espaços inovadores de qualificação, em que se observa a partilha de alguns compromissos e responsabilidades entre diferentes segmentos institucionais interessados no magistério".

Os saberes publicizados mediante apresentações em congressos nacionais, regionais, locais e os trabalhos de conclusão de curso primaram pela desvinculação da jurisprudência particular validada dos saberes docentes, constituindo este um ponto de entrave na sistematização das atividades do magistério. Desse modo, relacionou-se a divulgação dessas ações aos saberes legitimados, corroborando com Gauthier (2013, p. 125):

Enquanto a prática docente permanecer confinada ao segredo, protegida por trás das portas fechadas das salas de aula, os professores não poderão se esquivar dessa responsabilidade ética relativamente ao conhecimento dos meios que podem ser validados pela pesquisa. A partir, porém, do momento em que a pesquisa é realizada no ambiente da sala de aula, trata dos professores, de suas concepções prévias, de seus pensamentos, de suas ações e de seus efeitos sobre os alunos, então é difícil poder ignorar indefinidamente o que se faz sem mais cedo ou mais tarde ter de prestar contas diante da comunidade. 
Ao analisarmos a confluência desses saberes que foram articulados nas atividades desenvolvidas pelos bolsistas do Pibid nas escolas de Educação Básica, propomos uma avaliação das relações formativas estabelecidas entre as instituições universitárias, as escolas envolvidas no processo e a divulgação desses trabalhos colaborativos como meio de aprimoramento profissional.

\section{Análise e Discussão dos Resultados}

Ao avaliar os resultados obtidos por meio da sistematização e divulgação das ações desenvolvidas pelo Pibid/Química e suas contribuições na formação da identidade docente dos licenciandos da Ufes vinculados ao Programa, foi possível constatar as potencialidades deste na formação inicial de professores. Nesse sentido, foram enfatizadas as ações da instituição como um todo e não de cada campus separadamente. Apresentamos, no Gráfico 1, a sistematização dos resultados dessa categorização, de acordo com o ano em que foram desenvolvidas:

Gráfico 1 - Resultado da sistematização dos saberes docentes nos relatórios do Pibid/Ufes no período de 2012 a 2014

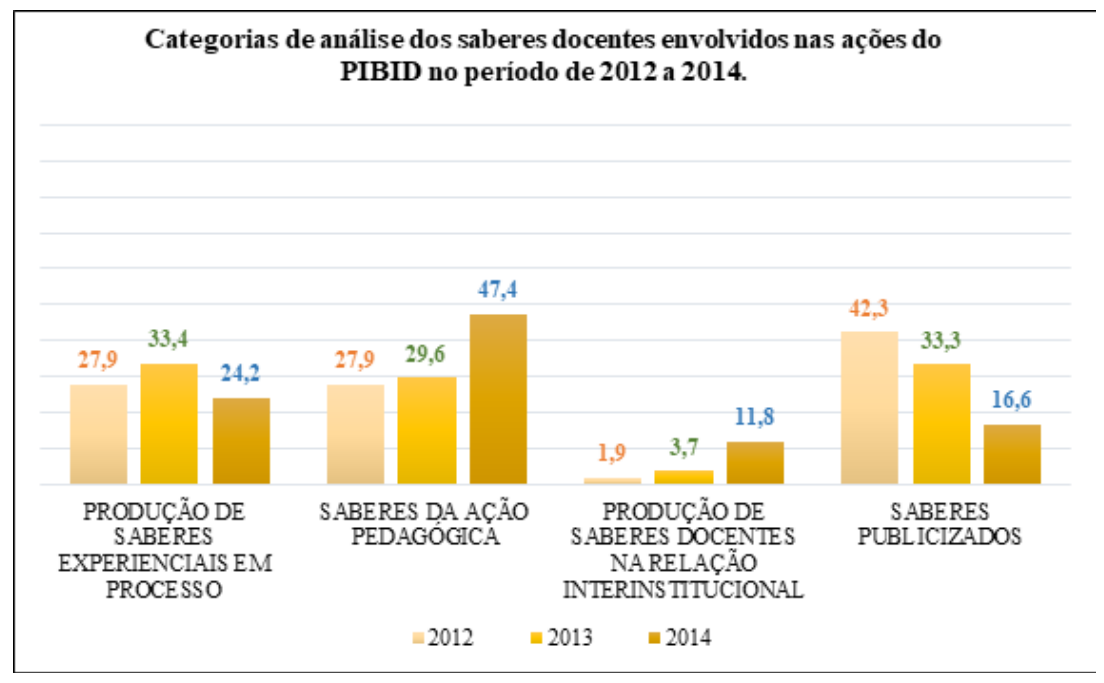

Fonte: Autoria própria. 
Sobre o Gráfico 1 é importante ressaltar que, no ano de 2013 foram disponibilizados para análise apenas os relatórios de dois subprojetos do Pibid/ Química/Ufes. Os resultados demonstram como as categorias de análise foram se aprimorando ao longo do período analisado, por exemplo, os Saberes da ação pedagógica e a Produção de saberes docentes na relação interinstitucional, tendo em vista a dinâmica de pesquisa pedagógica que requer vinculação dessas ações desenvolvidas a aspectos teóricos, filosóficos, metodológicos que regem a pesquisa acadêmica. $\mathrm{Na}$ análise dos saberes publicizados e na Produção de saberes experienciais em processo houve uma variação considerável da sua ocorrência no período avaliado, com a falta de um relatório sendo considerada ponto impactante nos resultados obtidos, entre outros que serão discutidos a seguir.

Assim, os nomes de escolas de Educação Básica, subprojetos do Pibid, bolsistas e quaisquer possíveis identificações do local em que se efetivaram foram substituídos por codinomes, com o intuito de voltar as reflexões advindas deste trabalho para as contribuições que o Pibid/Química/Ufes vem promovendo na formação inicial de professores.

As atividades de produção de saberes experienciais, em processo, requerem do profissional atitudes de planejamento conceitual com objetivos pedagógicos bem definidos, capacidade de agir e organizar o trabalho com um número significativo de alunos, mediar as ações que serão desenvolvidas a fim de se obter um resultado positivo no processo de ensino e aprendizagem. Essa dinâmica concretiza-se nas ações de cunho prático que se desenvolvem ao longo da vida profissional, no fazer e refazer prático, analisando os equívocos e os acertos que serão aprimorados em ações futuras. Esses saberes se constroem e reconstroem durante o período de aprendizagem do bolsista nas escolas de Educação Básica, visto que, por meio do programa Pibid o licenciando permanece em contato com a rotina profissional antes de sua entrada definitiva no mercado de trabalho.

No Quadro 1 destacamos algumas atividades que foram realizadas no período avaliado, representando a produção de saberes experienciais em processo que foram desenvolvidas nas atividades do subprojeto Pibid/Química/Ufes. Os termos destacados em negrito relacionam-se com os saberes que foram produzidos dentro dessa categoria: 
Quadro 1 - Atividades desenvolvidas no Pibid/Ufes relacionadas aos saberes experienciais em processo

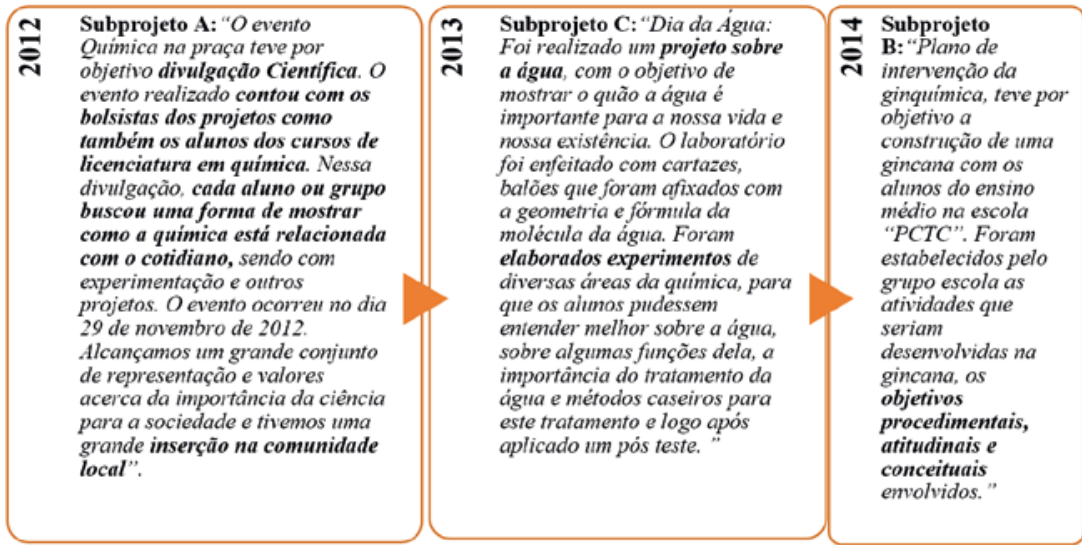

Fonte: Relatórios do Pibid/Química/Ufes.

Tardif (2014, p. 58) analisa os saberes envolvidos na epistemologia da prática: "Saberes mobilizados e empregados na prática cotidiana, saberes esses que dela provêm, de uma maneira ou de outra, e servem para resolver os problemas dos professores em exercício". A necessária interação, que se estabelece entre aluno e professor, é construída no dia a dia escolar por meio das atividades propostas e pela necessidade de aprendizagem. É um movimento que se aprende a executar ao longo da carreira docente, com as atividades de monitoria, promoção de feiras e clubes de Ciências, exposições e outros, constituindo momentos privilegiados de mediação e interação dos sujeitos envolvidos no processo.

Ao analisar as ações que envolvem a produção de saberes experienciais em processo na realização de monitorias, clubes e feiras de Ciências, exposições, gincanas do conhecimento e outros, constata-se uma movimentação contínua em direção à superação de um sistema de ensino propedêutico, pautado na relação verticalizada entre aluno e professor por meio da transmissão de conhecimento. Um movimento de mão única, que por décadas manteve o ensino em estado latente, mas atualmente se reelabora por meio da identificação de mudanças urgentes, como cita Miranda (2012, p. 129): 
É preciso formar diferentemente os professores, dizem-nos, porque o mundo mudou, porque a escola que já era insuficiente não consegue corresponder às exigências desse novo mundo, porque as práticas pedagógicas são autoritárias, os currículos, elitistas, tudo se informatizou, [...] a escola precisa se abrir para a participação da comunidade, os alunos devem construir seu próprio conhecimento e também os professores precisam reconstruir seus conhecimentos e suas práticas. Enfim, um mundo novo, com novos problemas, novos significados, novas exigências, novas soluções, novas práticas e, consequentemente, novos professores.

O desenvolvimento de ações como divulgação científica e projetos interdisciplinares oportuniza aos sujeitos em formação vencerem as barreiras excessivamente conteudistas, ao perceber a necessidade de movimentar saberes que contribuem no planejamento das atividades, nas pesquisas envolvidas na temática, na articulação entre os conhecimentos planejados e os que se desenvolvem ao longo da aplicação da atividade. Saberes estes para além do conhecimento exclusivamente curricular, que estejam vinculados aos sujeitos e suas necessidades formativas, ocupando-se em tecer elos entre estes e o contexto local em que os sujeitos envolvidos estão presentes.

Assim, analisar a importância da vivência formativa pautada nos novos (velhos) desafios educacionais e compreender e mediar o conhecimento como transformação social e não apenas conhecimentos vazios em si mesmos tornam-se pertinentes aos professores em formação, a fim de atentarem para a necessidade de processos de ensino que privilegiem a construção de saberes úteis à formação integral do sujeito (CHASSOT, 2014).

A percepção dos atributos docentes ao desempenhar as funções profissionais requer vivência e experiência não apenas dos aspectos disciplinares, mas também das condutas profissionais que, a todo instante, são convidadas a "participar" do processo educativo. Assim, ao conceber a necessidade de utilizar artifícios pessoais, como estabelecer proximidade com os alunos por meio da mediação de atividades, que impactam de maneira positiva na construção de conhecimento, é um ponto relevante na constituição da identidade docente, cuja lógica é avaliada por Tardif (2014, p. 276): “A lógica da socialização profissional, 
com seus ciclos de continuidades e de rupturas [...] suas urgências na tomada de decisões, seus momentos reflexivos mesclados de afetos e de proselitismo deve, progressivamente, excluir a lógica disciplinar como fundamento da formação".

Os bolsistas que vivenciam as atividades cotidianas nas escolas percebem essa característica como fundamental na estruturação dos saberes durante sua formação acadêmica, esse profissional prepara-se para o mercado de trabalho com mais propriedade em relação ao seu posicionamento perante os desafios da Educação Básica, por meio da reflexão na ação que acontece no decorrer do programa em cada atividade vivenciada. $\mathrm{O}$ estágio supervisionado cumpre seu papel em articular as experiências docentes no cotidiano escolar e as disciplinas do curso de Licenciatura, ampliando as vivências entre teoria e prática pedagógica. Já o Pibid possibilita aos licenciandos reconhecer o papel do poder público em que o ensino e a pesquisa docente se efetivam dentro da escola. E essa dinâmica corrobora com os autores aqui referenciados.

Apesar da recorrência ao modelo de ensino tradicional, em que o professor se apresenta como protagonista do processo de ensino e aprendizagem, até mesmo nos cursos de formação de professores, ainda se encontra arraigada na cultura docente a reprodução de modelos que captamos de nossos professores ao longo da vida estudantil, em que "acontece num processo interpessoal, [...] O professor em formação internaliza o processo e o reconstitui para si, constituindo-se professor" (MALDANER, 2013), ora reproduzindo, consciente, ações que aprendemos nesse processo, ora inconscientemente, pelo fato de esse tipo de aprendizado ter marcado nossa história de vida, de uma forma positiva ou não.

Por meio de atividades como as citadas no relatório, os bolsistas do Pibid vêm articulando suas ações na tentativa de reconstrução do fazer docente por meio da superação de ações pedagógicas nada exitosas, como cita Maldaner (2013, p. 389):

É um processo em que o professor domina toda a situação e a aula se desenvolve longe do diálogo e da participação ativa dos alunos. Em tal processo, não há lugar para a reconstrução criativa do conhecimento e os alunos desenvolvem crenças tácitas do que seja conhecimento, ciência, ensino, aprendizagem, papel do professor, papel do aluno, aula, programa de ensino, etc. Essas crenças influenciam profundamente a atuação profissional dos professores. 
Pimenta e Ghedin (2012, p. 157) avaliam a dimensão reflexiva do trabalho intelectual docente diante da articulação entre as ações que se apresentam na realidade escolar e a constituição da identidade docente: "Conceber o trabalho dos professores e professoras como trabalho intelectual quer dizer, pois, desenvolver um conhecimento sobre o ensino que reconheça e questione sua natureza socialmente construída $[\ldots]$ ".

Ao analisar os saberes da ação pedagógica nas atividades desempenhadas pelos bolsistas do Pibid, verificamos as oportunidades ofertadas com a participação no planejamento escolar, organização e registro de atividades propostas aos alunos da Educação Básica e avaliação das metodologias de ensino no cotidiano escolar. Foram produzidos materiais de registros de atividades como: portfólio, que teve como principal objetivo a organização dos textos, relatos, entre outras atividades realizadas pelos bolsistas; o caderno de registros, cujo objetivo foi relatar de forma reflexiva todas as atividades desenvolvidas pelos bolsistas de maneira individual e em grupos; diários de campo com apontamentos e relatos reflexivos avaliativos de todas as atividades executadas pelos bolsistas durante $o$ ano, além das avaliações diagnósticas que analisaram as dificuldades dos alunos em determinados conteúdos da disciplina de Química. Também foram utilizadas ferramentas de registro de atividades como relato reflexivo da intervenção na aula, que foi realizado de modo a refletir acerca das potencialidades e fragilidades ocorridas durante a intervenção e do planejamento feito das atividades desenvolvidas nas escolas de Educação Básica.

A reflexão das atividades docentes pensadas e repensadas por meio dos resultados obtidos nas ações desenvolvidas nas escolas e a compreensão de sua análise foram feitas por Zeichner (1992 apud PIMENTA; GHEDIN, 2012, p. 31):

[...] a partir de pesquisas que se desenvolvem junto as escolas e aos professores, formula três perspectivas a serem acionadas juntamente: a) a prática reflexiva deve centrar-se tanto no exercício profissional dos professores por eles mesmos, quanto nas condições sociais em que esta ocorre; b) o reconhecimento pelos professores de que seus atos são fundamentalmente políticos e que, portanto, podem se direcionar a objetivos democráticos emancipatórios; c) a prática reflexiva, enquanto prática social, só pode se realizar em coletivos, o que leva à necessidade de transformar as escolas em comunidades de aprendizagens nas quais os professores se apoiem e se estimulem mutuamente. 
Essas ações docentes contribuem para o desenvolvimento da profissionalização do ensino, visto que a dinâmica em que ocorreram permitiram aos bolsistas do Pibid uma avaliação sistemática dos pontos favoráveis e desfavoráveis da utilização de cada metodologia de ensino; a percepção do envolvimento dos alunos em cada atividade proposta; o trabalho concreto com métodos de ensino, trabalhos interdisciplinares, planejamento pedagógico, mapas conceituais; e avaliação dos conhecimentos prévios dos alunos envolvidos nas atividades nas escolas de Educação Básica.

Ao relacionar os saberes da ação pedagógica com a constituição da identidade docente percebeu-se o enfretamento da prática e suas saídas pedagógicas, envolvendo o aprofundamento nos aspectos conceituais das teorias e métodos de ensino, que possibilitaram aos futuros docentes desenvolver esquemas práticos que orientaram a ampliação efetiva das ações pedagógicas (FAZENDA, 1995, p. 22). Temos no Quadro 2 algumas atividades apresentadas nos relatórios, como forma de exemplificar os saberes da ação pedagógicas, sendo este um movimento em articulação com os subprojetos Pibid:

Quadro 2 - Atividades desenvolvidas no Pibid/Ufes relacionadas aos saberes da ação pedagógica

\begin{tabular}{|c|c|c|c|c|c|}
\hline$\frac{N}{\stackrel{N}{~}}$ & 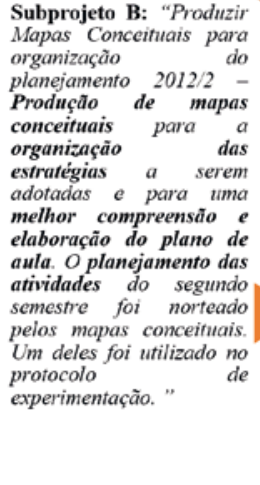 & $\frac{m}{\stackrel{N}{N}}$ & 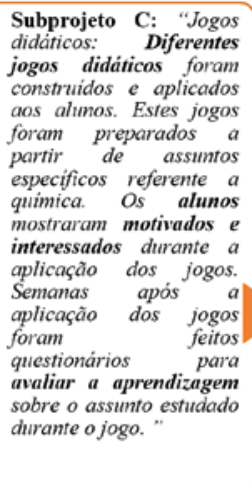 & $\frac{ \pm}{\delta}$ & 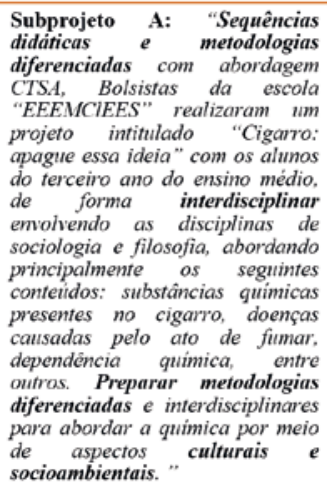 \\
\hline
\end{tabular}

Fonte: Relatórios do Pibid/Química/Ufes.

Os saberes da ação pedagógica evidenciam que os bolsistas do Pibid reconhecem formalmente a profissão docente, perante a epistemologia da prática, por meio das condições concretas que estes vivenciaram, ao se relacio- 
narem com suas "ferramentas de trabalho", como: metodologias diferenciadas de ensino; aulas experimentais; planejamento de atividades conduzidas por teorias do processo de ensino e aprendizagem; contextualização do ensino; processo motivacional do aluno, despertando seu interesse pelas Ciências e pelo conhecimento; avaliação diagnóstica dos conhecimentos prévios dos alunos; reuniões e registros pedagógicos; estratégias de ensino para alunos com necessidades especiais de aprendizagem, além de uma gama de situações de saber que somente a vivência do cotidiano escolar promove ao bolsista em formação, com o Pibid constituindo uma prática formativa que vem articulando importantes mudanças.

A dinâmica do trabalho colaborativo na produção de saberes docentes na relação interinstitucional permitiu inferir considerações acerca do benefício trazido à formação inicial e continuada dos envolvidos. A relação entre os bolsistas e os professores da Educação Básica possibilitou a troca de conhecimentos entre profissionais mais experientes e os bolsistas, que levaram para as escolas de Educação Básica novidades teórico-metodológicas disponibilizadas nas aulas da Graduação, visando a contribuir com o aperfeiçoamento do processo de ensino e aprendizagem. Ou ainda, as experiências compartilhadas pelos professores supervisores da Educação Básica serviram de apoio e discussão nas aulas da Graduação, como fonte de saberes que ocorreram na rotina escolar. Esse processo oportunizou aos coordenadores de área atribuir significados as suas aulas, visto a potencialidade de estruturar saberes com os bolsistas por meio das experiências que estes vivenciaram durante a realização das atividades do programa Pibid. Apresentamos no Quadro 3 alguns exemplos dessas ações interinstitucionais e as interações que estas conferiram à formação inicial dos bolsistas vinculados ao Pibid: 
Quadro 3 - Atividades desenvolvidas no Pibid/Ufes relacionadas aos saberes docentes na relação interinstitucional

\begin{tabular}{|c|c|c|c|c|c|}
\hline 글 & $\begin{array}{l}\text { Subprojeto B - "As reumiões } \\
\text { que eram realizadas todas as } \\
\text { quartas-feiras visavam } \\
\text { discutir e planejar as } \\
\text { atividades que seriam } \\
\text { realizadas nas escolas e } \\
\text { também verificar como estava } \\
\text { o andamento das mesmas nas } \\
\text { escolas. Assim, participavam } \\
\text { das mesmas o coordenador } \\
\text { de área do projeto, } \\
\text { professores responsáveis pelo } \\
\text { desenvolvimento do projeto } \\
\text { nas escolas. Além disso, } \\
\text { alguns artigos vinculados ao } \\
\text { ensino de quimica tambèm } \\
\text { eram trabalhados. Objetivos } \\
\text { alcançados: Maior interação } \\
\text { com os professores, além de } \\
\text { ser um horário ideal para } \\
\text { plamejar as atividades e } \\
\text { discuti-las juntamente com o } \\
\text { grupo. " }\end{array}$ & 商 & $\begin{array}{l}\text { Subprojeto A "Conhecer o } \\
\text { referencial CTSA e } \\
\text { desenvolver sequências } \\
\text { didáticas nessa abordagem. } \\
\text { Bolsistas e supervisores } \\
\text { participaram de um curso } \\
\text { de formação ministrado pelo } \\
\text { Prof. "S" e pela Prof. " } R \text { " } \\
\text { sobre abordagem CTSA } \\
\text { (Ciência, Tecnologia, } \\
\text { Sociedade e Ambiente) no } \\
\text { ensino de química e } \\
\text { desenvolvimento de } \\
\text { sequências didáticas. As } \\
\text { atividades totalizaram } 30 \\
\text { horas no més de agosto de } \\
\text { 2013. Curso de formaçăo } \\
\text { realizado com } \\
\text { aprofimdamento sobre o } \\
\text { referencial CTSA e } \\
\text { elaboração de sequências } \\
\text { didáticas sobre os temas } \\
\text { abordados nos projetos. } \\
\text { Reconhecer o espaço } \\
\text { escolar; conhecer o perfil } \\
\text { dos alumos, identificar a } \\
\text { forma como os profissionais } \\
\text { da escola trabalham e fazer } \\
\text { o estudo do projeto } \\
\text { pedagógico." }\end{array}$ & $\stackrel{\Xi}{\bar{\sim}}$ & $\begin{array}{l}\text { Subprojeto C - } \\
\text { "Reuniāo com o } \\
\text { Professor da Escola. } \\
\text { Acertar as datas, para a } \\
\text { apresentaçđo das } \\
\text { Intervenç̧es outras e } \\
\text { Intervençđo Aula na } \\
\text { escola. Reumião } \\
\text { quinzenal, para } \\
\text { determinarmos como } \\
\text { seria o andamento das } \\
\text { atividades que seriam } \\
\text { realizadas na escola, no } \\
\text { ano de } 2014 \text {. Relato } \\
\text { Reflexivo no Diário de } \\
\text { Bordo." }\end{array}$ \\
\hline
\end{tabular}

Fonte: Relatórios do Pibid/Química/Ufes.

A interação entre os pares envolvidos, o reconhecimento do tempo e espaço escolar, a troca de experiências entre os profissionais participantes do programa, bem como a percepção dos movimentos que ocorreram por meio da parceria escola/universidade, apresentaram-se como possibilidade de trabalho colaborativo fundamentado nas vivências formativas com o objetivo de agregar competências advindas da dimensão pedagógica à formação docente. Foerste (2005, p. 114) tece considerações acerca das necessidades de superação das condições de parceria entre universidade e escola:

Nessa modalidade de relação, a instituição formadora - a universidade - detém todo o poder de decisão, do que fazer e como fazer, principalmente nos chamados estágios curriculares. O estabelecimento escolar é tomado como um meio de aprendizagem daquele conjunto de aspectos práticos exigidos nos currículos dos cursos de formação inicial. Os professores da escola básica são considerados uma espécie de consultores, de caráter marcadamente burocrático, que cumprem tarefas num dado projeto pensado e conduzido pela academia. 
E é exatamente com esse propósito que o programa Pibid demonstrou seu potencial em articular saberes formativos da universidade com saberes construídos nas escolas de Educação Básica. As possibilidades concretas de dialogar, discutir e refletir as ações docentes por meio de vivências formativas no Pibid talvez seja um dos pontos a se analisar ao comparar o êxito do Programa com as necessidades formativas que o estágio supervisionado não alcançou. Por meio de formações voltadas a atender às necessidades que se apresentam no cotidiano escolar, a produção de saberes na relação interinstitucional movimentou o (re) pensar dos currículos nos cursos de formação docente, a partir da demanda em suprir a estruturação de conhecimentos que esta formação ou o estágio supervisionado não abarcaram.

A todo instante os bolsistas foram convidados a estabelecer relações com os sujeitos envolvidos, que vão desde as escolas de Educação Básica, com seu corpo pedagógico e administrativo, até as ações desenvolvidas na universidade, como os minicursos, as palestras, as reuniões de planejamento e compartilhamento dos resultados das atividades dos bolsistas.

A movimentação dos saberes publicizados mediante apresentações em congressos nacionais, regionais, locais e os trabalhos de conclusão de curso primaram pela desvinculação da jurisprudência particular validada dos saberes docentes, sendo este um ponto de entrave na sistematização das atividades do magistério. Desse modo, relacionou-se a divulgação dessas ações aos saberes legitimados, corroborando com Gauthier (2013, p. 125):

Enquanto a prática docente permanecer confinada ao segredo, protegida por trás das portas fechadas das salas de aula, os professores não poderão se esquivar dessa responsabilidade ética relativamente ao conhecimento dos meios que podem ser validados pela pesquisa. A partir, porém, do momento em que a pesquisa é realizada no ambiente da sala de aula, trata dos professores, de suas concepções prévias, de seus pensamentos, de suas ações e de seus efeitos sobre os alunos, então é difícil poder ignorar indefinidamente o que se faz sem mais cedo ou mais tarde ter de prestar contas diante da comunidade. 
À medida que os bolsistas do Pibid são formados sob essa ótica de divulgação e pesquisa do seu trabalho, eles se tornam mais conscientes e aptos a desenvolverem ações futuras, que venham romper com a vinculação de suas atividades ao sigilo do seu ofício. Outra questão pertinente a essa análise é apresentada por André (2012, p. 59):

É extremamente importante que o professor aprenda a observar, a formular questões e hipóteses e a selecionar instrumentos e dados que o ajudem a elucidar seus problemas e encontrar caminhos alternativos na sua prática docente. E, nesse particular, os cursos de formação desempenham um importante papel: o de desenvolver, com os professores, essa atitude vigilante e indagativa, que os leva a tomar decisões sobre o que fazer e como fazer nas suas situações de ensino, marcadas pela urgência e pela incerteza.

Ao avaliar os saberes publicizados desenvolvidos pelos bolsistas do Pibid que foram divulgados, percebemos o potencial em construção de conhecimentos úteis à prática profissional por meio das reflexões nas ações, como também a oportunidade aos bolsistas da elaboração de mecanismos práticos que lhes permitam executar pesquisas e a sua divulgação, tendo como campo investigativo o ambiente escolar. O Programa vem promovendo possibilidades de reflexão do ambiente escolar que vão além da estrutura disciplinar do curso, com maiores habilidades de articulação das pesquisas acadêmicas em relação ao cotidiano escolar capaz de validar as ações docentes. Nos fragmentos retirados dos relatórios são apresentados no Quadro 4 alguns saberes que foram publicizados, por diversos meios de divulgação: 


\section{Quadro 4 - Atividades desenvolvidas no Pibid/Ufes relacionadas aos saberes publicizados}

\begin{tabular}{|c|c|c|c|c|c|}
\hline 글 & $\begin{array}{l}\text { Subprojeto B } \\
\text { "Tipo do produto: artigo } \\
\text { técnico-cientifico com } \\
\text { denominação "Saberes } \\
\text { inerentes à docência: o } \\
\text { que um professor tem } \\
\text { que saber?", publicado } \\
\text { na Revista FACEVVn. } \\
\text { especial, jan. / jun. de } \\
\text { 2012." }\end{array}$ & 承 & $\begin{array}{l}\text { Subprojeto A } \\
\text { "Divulgar as atividades e os } \\
\text { resultados dos subprojetos em } \\
\text { eventos cientificos locais, regionais } \\
\text { e nacionais para incentivar a } \\
\text { participação dos bolsistas e } \\
\text { promover acesso a novas } \\
\text { informações. Participação de } \\
\text { bolsistas da escola "EEEMCR" no } \\
53^{\circ} \text { Congresso Brasileiro de } \\
\text { Quimica, realizado no Rio de } \\
\text { Janeiro - RJ, com apresentação do } \\
\text { trabalho intitulado "Utilização de } \\
\text { Experimentos problematizadores } \\
\text { com enfoque CTSA nas práticas do } \\
\text { PIBID como promoção da educação } \\
\text { cientîfica no ensino de quimica". } \\
\text { Apresentação de trabalho na } \\
\text { modalidade pôster." }\end{array}$ & 竝 & $\begin{array}{l}\text { Subprojeto C } \\
\\
\text { "O trabalho intitulado } \\
\text { "Tabela Periódica } \\
\text { portátil em Braille: Sem } \\
\text { limitaçóes a uma } \\
\text { aprendizagem } \\
\text { significativa:" foi } \\
\text { apresentado no XVII } \\
\text { ENEQ 2014 - Encontro } \\
\text { Nacional de Ensino de } \\
\text { Quimica, em Ouro } \\
\text { Preto, Minas Gerais." }\end{array}$ \\
\hline
\end{tabular}

Fonte: Relatórios do Pibid/Química/Ufes.

Foerste (2005) aponta algumas condições necessárias para a realização de pesquisas, e consequentemente a sua divulgação, ao tecer considerações sobre as circunstâncias concretas de sua efetivação na parceria entre Universidade e escolas de Educação Básica, como uma preanunciação à instituição do programa Pibid, quatro anos antes do seu início. No que tange os resultados aqui apresentados, mesmo que iniciais, da publicização dos saberes docentes e a demanda urgente de dispositivos de reformas educacionais, propomos a seguinte reflexão entre os resultados obtidos dos saberes publicizados pelo Pibid no Espírito Santo que corroboram com Foerste (2005, p. 111):

As escolas de Educação Básica são os lócus que funcionam como uma espécie de laboratório de ideias e práticas educativas, em cujo seio há muito acertos (aspectos a serem destacados e divulgados) e também desacertos (vícios a serem superados). Nem sempre tudo o que acontece no cotidiano escolar é partilhado ou dito pelos docentes para profissionais de fora. Pesquisar o cotidiano escolar e suas ambiguidades, a fim de elaborá-las criticamente, para se colocar no movimento pela transformação da escola, são dimensões constitutivas de um paradigma emergente na formação de professores, visando à valorização do trabalho docente e do ensino público emancipatório em todos os seus níveis. 
A divulgação desses e outros saberes nos relatórios do Pibid, portanto, oportunizou a difusão pela ótica da pesquisa aplicada tanto no planejamento das ações quanto nas conclusões e publicação dos resultados via pesquisa que ocorreu no local de desenvolvimento de saberes e ações da identidade docente: a sala de aula.

Observamos no Gráfico 1 uma diminuição dos saberes publicizados, que pôde ser atribuída após identificação de quais foram os eventos científicos em que os bolsistas do Pibid participaram com o envio e apresentação de trabalhos de pesquisa. ${ }^{4}$ Outro fator que pode ter contribuído para a diminuição do número de trabalhos publicados é o fato de que nos últimos anos houve cortes de verbas para o Programa.

Os relatórios enviados à Capes oportunizam publicizar as atividades que os bolsistas do Pibid desenvolvem, com o objetivo de aprimoramento das atividades didático-pedagógicas. Dessa forma, a jurisprudência particular do ofício docente é divulgada, tornando-se objeto de reflexão das atividades dos professores.

Os saberes publicizados oportunizaram aos licenciando a divulgação de suas ações por meio da prática pedagógica, conferindo a estes autonomia docente em relação ao fazer pedagógico. Por meio da publicação de suas reflexões e experiências vivenciadas no ambiente escolar, o licenciando deixa a jurisprudência particular do seu trabalho e anuncia a epistemologia da prática como fonte de informação do trabalho docente.

\section{Considerações}

Em virtude da possibilidade de fusão entre os profissionais que são educadores e também pesquisadores, o Pibid potencialmente agrega saberes produzidos nas ações desenvolvidas a partir da prática docente, advindas da produção de saberes e nas relações entre teoria e prática, principalmente mediante a publicização dos saberes docentes.

${ }^{4}$ Os eventos em que houve apresentação de trabalhos foram: no ano de 2012 - III Encaqui/II Encontro Estadual do Pibid/XVI Eneq/XXVI SBQ. No ano de 2013 - 36 $6^{\circ} \mathrm{SBQ} / 65^{\mathrm{a}} \mathrm{SBPC} / \mathrm{II}$ SMEQ/IV Encaqui/53 $3^{\circ} \mathrm{CBQ}$. No ano de 2014 - 54 ${ }^{\circ} \mathrm{CBQ} / \mathrm{II}$ Seminário Pibid/XVII Eneq. 
As concepções da prática formativa oportunizada aos licenciandos do Pibid - de se inserirem na vida profissional com bagagem teórica e experiencial baseada na epistemologia da prática - renovam saberes a cada tentativa do fazer docente, exitosa ou não, pautando a reflexão na ação docente que se concretiza no (re)fazer, no ambiente escolar, anunciando (em conjunto) aos pares envolvidos um movimento constante de construção e reconstrução da identidade docente.

Entendemos que o programa Pibid veio oferecer aos centros de formação docente desafios e possibilidades de mediar ações efetivas que ocorrem ao longo de um curso de Licenciatura e não em momentos isolados. Somente vivências esporádicas do trabalho docente não são suficientes para abarcar as necessidades complexas e formativas do profissional do magistério. Assim sendo, o programa Pibid apresenta-se como mais uma possibilidade de (re)construção de saberes docentes.

O protagonismo do professor em formação em publicizar sua prática confere a esse profissional uma autonomia docente perante os desafios de sistematizar os saberes que se estruturam nas ações pedagógicas. Ao utilizar os registros das atividades, pelos diversos meios aqui apresentados, proporcionou-se ao futuro professor refletir criticamente suas ações e os resultados obtidos, reavaliar por meio das interfaces estabelecidas entre saberes em processo advindos das vivências nas escolas de Educação Básica e os saberes acrescidos na formação acadêmica como saída da jurisprudência particular, para tornar por meio da validação anunciada a epistemologia da prática como fonte de informação e formação do trabalho docente. Se os saberes publicizados advêm de uma movimentação que ocorre, a princípio, em uma atividade que foi pensada e preparada a partir de uma necessidade imediata de aprendizagem, na sala de aula, em um segundo momento os bolsistas conferem a essa atividade o caráter de pesquisa, à luz dos procedimentos investigativos desta, como um processo de construção de conhecimento docente, que é posto à validação, por intermédio da divulgação em congressos, periódicos e em outros meios. 
Analisar a potencialidade do Pibid/Química/Ufes na produção de saberes contribui na constituição da identidade docente, revelando-se a ocorrência dessa mobilização uma forma processual de formação profissional que não se limita ao tempo em que ocorre, tornando-se instrumento que servirá de apoio ao trabalho docente.

Considerar a subjetividade da escrita que aparece nos relatórios - especialmente a qualidade e compromisso com o texto escrito, como a descrição das atividades, às vezes de maneira superficial - é um ponto de reflexão da sistematização ora apresentada.

Uma fragilidade que o programa precisa superar é o fato de cada subprojeto se desenvolver de acordo com as competências de quem o orienta, sem sistematização definida, sendo orientado pela experiência profissional de quem o executa. Só toma conhecimento das ações desenvolvidas nos subprojetos quem participa dos encontros anuais, ou regionais. A Capes tem o potencial de divulgação das ações docentes, por meio dos relatórios e isto poderia tornar público a gama de informações pertinentes a um fazer docente que ocorreu na tentativa de superação dos desafios da prática escolar.

Nessa perspectiva, as Universidades têm em mãos os resultados dessa experiência, vislumbrando a oportunidade de dar continuidade ao programa, a partir de um modelo que contribui de maneira significativa para a formação de professores.

\section{Referências}

ANDRÉ, M. (Org.). O papel da pesquisa na formação e na prática dos professores. 12. ed. Campinas, São Paulo: Papirus, 2012.

BARDIN, L. Análise de conteúdo. Tradução Luís Antero Reto e Augusto Pinheiro. São Paulo: Edições 70, 2011. p. 279.

CHARLOT, B. Formação de professores: a pesquisa e a política educacional. In: PIMENTA, S. G.; GHEDIN, E. (Org.). Professor reflexivo no Brasil: gênese e crítica de um conceito. 7. ed. São Paulo: Cortez, 2012. p. 103-126.

CHASSOT, A. Para que(m) é útil o Ensino? 3. ed. Ijuí: Ed. Unijuí, 2014. 
FELDMANN, G. (Org.). Formação de professores e escola na contemporaneidade. São Paulo: Ed. Senac, 2009.

FAZENDA, I. C. A. A academia vai à escola. Campinas, SP: Papirus, 1995. 238 p.

FOERSTE, E. Parceria na formação de professores. São Paulo: Cortez, 2005.

GATTI, B. A. Estudos quantitativos em educação. Educação e Pesquisa, São Paulo, v. 30, n. 1, p. 11-30, jan./abr. 2004. Disponível em: <http://www.scielo.br/pdf/ep/v30n1/ a02v30n1.pdf>. Acesso em: 5 ago. 2016.

GAUTHIER, C. et al. Por uma teoria da pedagogia: pesquisas sobre o saber docente. Tradução: Francisco Pereira. 3. ed. Ijuí: Ed. Unijuí, 2013. p. 480. (Coleção Fronteiras da Educação).

GIL, A. C. Métodos e técnicas de pesquisa social. 6. ed. São Paulo: Atlas, 2008.

HUBERMAN, M. O ciclo de vida profissional dos professores. In: NÓVOA, A. (Org.). Vidas de professores. Porto: Porto Editora, 1992.

MALDANER. O. A. A formação inicial e continuada de professores de química: professor/pesquisador. 4. ed. Ijuí: Ed. Unijuí, 2013. 424 p. (Coleção Educação em Química). MIRANDA, M. G. de. O professor pesquisador e sua pretensão de resolver a relação entre a teoria e a prática na formação de professores. In: ANDRÉ, M. E. D. A. de. (Org.). O papel da pesquisa na formação e na prática dos professores. Campinas: Ed. Papirus, 2012. p. 129-143.

PIMENTA, S. G.; GHEDIN, E. (Org.). Professor reflexivo no Brasil: gênese e crítica de um conceito. 7. ed. São Paulo: Cortez, 2012.

TARDIF, M.; LESSARD, C.; LAHAYE, L. Os professores face ao saber: esboço de uma problemática do saber docente. Teoria e Educação, Porto Alegre, n. 4, p. 215-133, 1991.

TARDIF, M. Saberes profissionais dos professores e conhecimentos universitários: elementos para uma epistemologia da prática profissional dos professores e suas conseqüências em relação à formação para o magistério. In: Revista Brasileira de Educação, n. 13 , jan. 2000 .

. Saberes docentes e formação profissional. 17. ed. Petrópolis, RJ: Vozes, 2014.

VARLOTTA, Y. M. C. Representação social de ciência constituída por alunos do ensino médio: porto de passagem da ação pedagógica. 2002. Tese (Doutorado). São Paulo: PUC-SP, 2002.

WELLER, W.; PFAFF, N. (Org.). Metodologias da pesquisa qualitativa em educação. 3. ed. Petrópolis, RJ: Vozes, 2013. p. 336. 